УДК $81 ’ 373.43$

DOI 10.37972/chgpu.2020.51.80.002

К. Н. Булатбаева, Г. К. Сарсикеева, К. Б. Айтжанов

\title{
ОККАЗИОНАЛЬНОЕ В СОВРЕМЕННОМ ЯЗЫКЕ: НОВЫЕ АСПЕКТЫ АНАЛИЗА
}

\author{
Евразийский национальный университет им. Л. Н. Гумилева, г. Нур-Султан, Казахстан
}

Аннотация. Статья посвящена окказиональным явлениям в лингвистике. Особое внимание уделено условиям проявления окказиональных значений - уровневым аспектам функционирования окказионализмов. Авторами установлено, что окказионализмы можно классифицировать по их функционированию в рамках разных единиц синтаксиса. Окказиональные сочетания впервые представлены в определенной классификации с целью системного рассмотрения их функционирования в рекламных текстах. Условиями проявления окказионального могут быть словосочетания, предикативные и полупредикативные сочетания слов, коррелирующие предикативные части сложного предложения, без анализа которых не будет ясно видна нестандартная семантика языковой единицы и соответственно суть этого явления. Также в работе выявлено, что семантическая параллель или семантическая противоположность служат средствами привлечения внимания читателей. В качестве иллюстративного материала использованы примеры из рекламных текстов и газетных статей.

Ключевые слова: окказионализм в словосочетаниях, окказионализм в полупредикативньх сочетаниях, окказионализм в предикативных сочетаниях, коррелирующие предикативные части, рекламньй текст.

K. N. Bulatbaeva, G. K. Sarsikeeva, K. B. Aytzhanov

\section{OCCASIONALISMS IN MODERN LANGUAGE: NEW ASPECTS OF ANALYSIS}

\section{N. Gumilyov Eurasian National University, Nur-Sultan, Kazakhstan}

Abstract. The article is devoted to the occasional phenomenon in linguistics. It pays special attention to the conditions of manifestations of occasional meanings, in other words, to the level aspects of the functioning of occasionalisms. The authors established that occasionalisms can be classified by their functioning within different syntactical units. The authors are the first to classify occasional combinations in order to systematically study their functioning in advertising texts. The conditions of occasional manifestation can be word combinations, predicative and semi-predicative combinations of words, even correlating predicative parts of a complex sentence. Without analyzing those conditions, it is impossible to determine the non-standard semantics of the language unit and, accordingly, the essence of this phenomenon. The authors also revealed that the semantic parallel or the semantic opposite attracts the attention of readers. They illustrate the work with the examples from advertising texts and newspaper articles.

Keywords: occasionalism in word combinations, occasionalism in semi-predicative combinations, occasionalism in predicative combinations, correlating predicative parts, advertizing text.

Актуальность исследуемой проблемы. Актуальность исследования определяется значимостью окказиональных явлений в современных текстах. Цель исследования - раскрыть единицы синтаксиса как условия выражения окказионального в лингвистике.

Материал и методика исследований. Материалом исследования явились тексты средств массовой информации. Использовались методы дискурсивного анализа, трансформации, сравнения, описания. 
Результаты исследований и их обсуждение. Лексический, словообразовательный и функционально-грамматический анализ через сопоставление семантических групп слов и составляющих их морфем, словообразовательных способов и словообразовательных рядов, синтаксических моделей позволяет выявлять новые аспекты окказиональных явлений в языке. Окказиональное сочетание слов представляет собой стечение лексем, которое нетипично для обычной речи. Эта необычность и новизна приковывают внимание читателя и слушателя. Поэтому окказиональная сочетаемость используется в особых целях, она противоречит закону семантического согласования вследствие отсутствия общих сем в лексических значениях их элементов. Появление контекстуально обусловленных семантических сдвигов в зависимом компоненте словосочетания способствует активизации мыслительной деятельности воспринимающего речь, который должен понять внутренние смысловые связи. Следует заметить, что до этого аналогичную мыслительную работу проделывал и автор окказионализма или окказионального сочетания. Но он полагался на личный опыт и собственное национально-культурное восприятие окружающего мира, поэтому ему нововведение было продиктовано его ментальным миром.

При определении окказионализма исследователи прежде всего противопоставляют его понятию узуса как привычного, традиционного, закономерного в языке. Так, сопоставление узуального и окказионального в языке мы находим в статье И. С. Улухановой [12].

Как известно, речь - это живое функционирующее явление, основанное как на традиционных стереотипных лексико-грамматических и словообразовательных моделях, так и на индивидуальном опыте познания человеком действительности, умении сравнивать и сопоставлять значения несопоставимых, на первый взгляд, явлений из разных семантических макрополей, способности заглянуть во внутреннюю форму слова и найти то общее, что позволяет сблизить разные явления. Такие неординарные мыслительные операции, реализуемые в речевых высказываниях, являются прерогативой людей с высокой способностью анализировать, абстрагировать, сравнивать, синтезировать, выявлять точки соприкосновения. В то же время немаловажным движущим мотивом является цель воздействовать на читателя или слушателя, заинтересовать его необычным названием, нацелить его взгляд на самую главную идею, тем самым привести к пониманию глубокого смысла текста и вызвать восхищение необычной языковой находкой.

В лингвистической науке давно известен термин «окказионализм», который понимается как необычное сочетание, присущее одной конкретной личности, но не воспроизводимое народом как носителем языка. В начале исследования этого феномена ученые прежде всего обращали внимание на отдельные слова. При этом окказиональные слова считались прерогативой писателей. У каждого лингвиста в памяти пушкинское слово «огончарован», которое указывает на индивидуальное словотворчество поэта.

Окказиональное словообразование рассмотрено в трудах Р. Ю. Намитоковой [4], Э. Ханпира [13], Л. А. Шеляховской и Н. А. Богданова [16]. Как известно, при образовании говорящим окказионализма внутри слова необычно компонуются определенные корневые и аффиксальные морфемы, которые передают новое значение, соответствующее замыслу автора речи. При этом внутренняя форма окказионального слова рассчитана на некий опыт носителей языка, которые при восприятии этого новообразования соотносят смыслы его компонентов, дают внутреннюю оценку автору за его изобретательность в умении передать всю ситуацию одним словом и расшифровывают идею говорящего. При этом каждая морфема как компонент окказионализма содержит национально-специфический социальный фон, который остается непонятным для неисконного носителя. Окказионализм привлекает внимание своей необычностью при первоначальном восприятии, интригует возможностью познать новое, незнакомое. Наиболее полное определение этому понятию дает Н. В. Титова [10]. 
Исследователь выделяет экспрессивность, невоспроизводимость, характерное нарушение языковых норм, постоянную новизну. В дополнение к идее автора о том, что окказионализмы представлены в рекламных текстах, можем отметить, что они часто встречаются в газетных статьях, особенно в заголовках (см. примеры ниже). Анализ окказионализмов на разных уровнях порождает спор об уровневом статусе этого явления. Одни ученые изучают его на уровне лексики и фразеологии, другие считают, что полную картину об окказионализме можно получить в рамках синтаксической единицы [17], [18].

Нужно отметить, что в настоящее время обширный поток информации в глобальном пространстве, стремление к лаконичности, широкий кругозор личности позволяют даже простому носителю языка порождать необычные слова.

Со временем лингвисты начали выявлять словообразовательные типы окказионализмов, определять степень их продуктивности, изучать функции, раскрывать экспрессивный и прагматический потенциал этих необычных языковых средств. Так, неузуальные образования с разных позиций рассматривает Л. И. Плотникова, которая на множестве примеров типа эсэнговский 'принадлежащий СНГ' в сравнении с однокоренными эсэнговый 'плохой', 'дорогой', эсэнгово 'плохо' раскрывает динамику отражения оценки в социальной, политической и экономической сферах в системе новообразований современного языка [6]. Можно привести и другие примеры словообразовательного плана, когда и автор, и воспринимающий (читатель/слушатель) имеют общий культурный фон, знают, из какого источника взято устойчивое сочетание, одно слово в котором намеренно созвучно и в то же время является антиподом художественного образа: название статьи Старуха ИЗВЕРГиль [8] точно передает преступление 71-летней пенсионерки.

При этом быстрая реакция на происходящие события, ориентация на осведомленность массового читателя или слушателя о текущем положении дел позволяют говорящему быстро поменять букву в слове, и тогда получаем его оценочную информацию: деnymam $\rightarrow$ жепутат (современный казахский поэт М. Шаханов), при этом интернациональное слово становится сугубо казахским за счет корня же-, за которым кроется глубокая негативная семантика присвоения, нечестного обогащения и т. д. (жеу 'есть', 'кушать' в исконном значении; во вторичном значении - 'присваивать') (из устного публичного выступления).

Таким образом, особенностью окказиональных явлений в русском языке является нестандартное словообразование, при котором меняется одна фонема, одна морфема, основа слова (на основе идентичности частей речи, схожести фонетического облика), и эти изменения понятны бывают лишь в контексте с учетом культурного фона.

Не менее значимы для понимания природы окказионализма и другие языковые единицы, кроме слова. В поддержку идеи выделения окказиональных единиц высшего порядка, нежели слово, выступает Н. Г. Бабенко [1]. Автор выделяет грамматические окказионализмы и рассматривает понятие окказионального в широком контексте.

В этой статье мы впервые представляем определенную классификацию окказиональных сочетаний с целью системного рассмотрения их функционирования в текстах СМИ. Таковыми могут быть словосочетания, предикативные и полупредикативные сочетания слов, даже коррелирующие предикативные части сложного предложения, которые привлекают внимание читателей семантической параллелью или семантической противоположностью.

Окказионализм в словосочетаниях. Часто в средствах массовой информации мы встречаем необычные сочетания, слова которых не входят в одно семантическое поле. Например, интересно название статьи Пляж на снегу, тогда как слово пляж в сознании носителя русского языка ассоциируется с летом, с горячим песком, а не снегом и зимой. 
Оказалось, это лаконичное название вида спорта - зимнего пляжного баскетбола [7]. Или название газетной статьи Горючие слезы метафорически, но точно передает проблемную ситуацию: стоимость грузоперевозок растет из-за повышения цен на топливо, а это ведет к подорожанию продуктов первой необходимости [2]. Окказиональный характер этих двух сочетаний в плане потенциального перехода в узус разный: при развитии описываемого вида спорта первое постепенно может стать узуальным, тогда как словосочетание горючие слезы, не поддерживаемое денотатом, останется исключительно авторским лексикограмматическим новообразованием. Так, из СМИ пришли и закрепились в языке такие сочетания, как люди в погонах, люди в бельлх халатах, так как они являются описательными названиями реально существующих субъектов (денотатов) - военных и полицейских, медицинских работников. Также новым объектом анализа могут служить окказиональные сочетания типа честное бандитское поздравление [15] как необычная калька известного в XX веке клише честное пионерское слово. Ассоциативную связь между двумя сочетаниями поддерживают не только лексема «честное», но и грамматическая модель.

Окказионализм в предикативных сочетаниях. Анализ современных текстов СМИ позволяет выявлять необычность авторского творчества не только в рамках слова и обычного словосочетания. Ведь неузуальное сочетание мы встречаем и в основе предложения-высказывания, которое может оставаться сугубо личным творчеством говорящего по конкретному случаю. До сих пор не затронут вопрос построения грамматических окказионализмов за счет трафаретных моделей прошлого жизненного опыта носителей языка: с советского времени известны строки из песни Нам дружба жить и ... помогает, которая в виде окказионального средства трансформирована во фразу Им служба грабить и бить помогает [3]. Здесь также обнаруживаем, что средствами ассоциативной параллели служат как лексическое средство, так и грамматическая структура. Известное устойчивое предикативное сочетание - название фильма «Москва слезам не верит» также из узуального переходит в окказиональное путем замены подлежащего на слово «суд» при передаче контекста о квартирной мошеннице: Суд слезам не верит [9]. Также в русскоязычной среде известна поговорка Голод - не тетка, которая легко по ситуации переходит в окказиональное сочетание Холод - не тетка [14], когда сообщается о невозможности учиться из-за холода в школьных кабинетах.

Окказионализм в полупредикативных сочетаниях. Его пожелания, приправленные криминальной романтикой, выглядели достаточно смечно [5]. В данном полупредикативном сочетании автором речи лексема «приправленные» из семантического поля «Питание» интегрируется сразу в два других поля - «Эмоциональный мир человека» и «Криминальная среда». Такое сочетание на уровне синтаксиса не рассматривалось как окказиональное сочетание, хотя на лексическом уровне отдельно взятое слово обычно анализируется как метафора.

Окказионализм в соотнесенности предикативных сочетаний в сложсных предложения. Частотность окказиональной параллели предикативных сочетаний в сложных предложениях также является новым объектом анализа. Не ограничиваясь одним конкретным языком, можем привести некоторые наблюдения за этим явлением. Например, лозунг Бүгін - Тен, ертең - сен! - окказиональный, разовый, хотя его произносят многие, так как он является резонансным после громкого убийства известного спортсмена (Денис Тен - казахстанский фигурист, погибший от рук грабителей). Впоследствии данный лозунг не будет актуальным, так как слово «бүгін», обозначающее актуальное трагическое событие, со временем уйдет в прошлое.

Итак, окказиональные сочетания имеют разные пути дальнейшего существования: а) исчезают в силу давности события или неподкрепленности денотатом; б) приобретают узуальный характер. Таким образом, соотношение узуального и окказионального в широ- 
ком понимании последнего требует дальнейшего глубокого изучения. Индивидуальная речь при лексикализации становится сплетением воспроизводимого и нового, необычного. Чем чаще используются сочетания несочетаемых лексем, тем увлекательнее становится речь говорящего. Такие сочетания подчеркивают интеллект человека, его умение неординарно мыслить. На уровне лексики окказионализмы хорошо выявляются, на уровне грамматики их следует определять на основании детального анализа контекста, дискурса, так как за одной предикативной основой может стоять целое событие. И важно также рассмотреть межъязыковое и территориальное функционирование этих лексикограмматических новообразований, так как последние носят локальный характер и могут быть непонятными за пределами страны или конкретной местности.

Для иллюстрации выявленных особенностей окказионального сочетания слов приведем такой текст рекламного характера:

Об этой услуге можно прочитать много интересной информации намногочисленных сайтах для автолюбителей. Трейд-ин - довольно популярный инструмент. Автовладелеи на своем автомобиле приезжает в автосалон, после чего отдает мамину на диагностику, а также на оценку её реальной стоимости. Таким образом, маиина «отдыхает» в салоне, а хозяин «тачки» ищет себе достойную замену в этом же автосалоне - жестокий по отноиению $\kappa$ «старуикее, но крайне удобный прочесс. Владелеч наконеч находит себе новую "автопассию», а «старуика», оцененная и исследованная по полной программе, терпеливо ожидает своей участи. Хозяин доплачивает салону за сервис и разницу между новой и старой маииной, после чего без каких-либо угрызений совести преспокойно уезжает домой на новой или не очень легковуике [11].

Простота текста и доступность лексики являются необходимым признаком рекламного текста. В то же время лексика, передающая лишь суть высказываемого, далеко не интересна. Она больше подходит при технической характеристике объекта продажи. А окказиональные сочетания придают тексту определенную эмоциональность, экспрессивность и вызывают неподдельный интерес воспринимающего. Поэтому значимы переносные значения слов в виде метафор, описательные замены ключевых слов. Далее, важно создавать для слушателя или читателя неофициальную обстановку за счет общенародной лексики, то есть копировать живой разговор покупателя и продавца. Такой способ создает эффект непринужденного общения, но в то же время перебор разговорной лексики может снизить уровень делового взаимодействия, в связи с чем целесообразно чередование стилистически нейтральной, эмоционально окрашенной и разговорной лексики. Окказиональные сочетания и сами окказионализмы привлекают внимание, хорошо запоминаются и вызывают положительные эмоции относительно объекта речи.

В [11] активно использованы олицетворение (маиина отдыхает, «старуика» терпеливо ожидает своей участи, новая автопассия), перифраз (достойная замена), эпитет (жестокий прочесс). Во-первых, эти стилистические приемы делают текст интересным и доступным, легко воспринимаемым слушателем или читателем. Относительно хозяина также применяются слова, которые передают легкость его действий: приезжает на своем автомобиле, отдает на диагностику, ищет замену, находит, доплачивает и без угрызений совести преспокойно уезжает домой. Особенность текста - разъяснить суть этого вида продажи. Во-первых, автор текста его называет инструментом, что необычно для всех носителей русского языка, так как это слово заменяет значения «вид или тип продажи», «механизм или способ продажи». За счет необычных сочетаний слов текст рекламы достигает своей цели: маиина отдыхает в салоне, сравним: машину оставляют в автосалоне / машина стоит в автосалоне / машина помещается в автосалон. Хозяин тачки ищет себе достойную замену в этом же автосалоне, сравним: продавец находит новый 
автомобиль в этом же автосалоне. Далее дана эмоционально-оценочная характеристика процесса продажи: жестокий по отношению $\kappa$ «старуике». За такой оценкой стоит старая машина хозяина, которую он продает. Лаконичность достигается за счет этого окказионализма-перифраза, являющегося таюже олицетворением.

Резюме. Наше исследование показало, что окказионализмы должны рассматриваться на уровне синтаксической единицы, в рамках которой они проявляют свое окказиональное значение. Показан новый аспект системного представления в пределах разных синтаксических единиц. Такой анализ позволит выявить типовые особенности выражения окказионального. Анализ на уровне лексики и фразеологии будет недостаточным, если не учитывать структурных условий порождения окказионального. С позиции дискурсивного анализа наиболее полную картину окказионализма можно получить в контексте, когда будут проанализированы не только само значение окказионализма, но и единица синтаксиса как условие выражения окказионального. Объем статьи не позволил нам разобрать более широкий спектр окказиональных явлений в разных контекстах, что станет объектом наших дальнейших исследований. Особенно интересным будет дискурсивный анализ окказионализмов с учетом культурного фона текстов.

\section{ЛИТЕРАТУРА}

1. Бабенко Н. Г. Окказиональное в художественном тексте. Структурно-семантический анализ. - Калининград : Калининград. гос. ун-т, 1997. -84 с

2. Гортчие слезы // Жизнь. - 20.11.2018.

3. Им служба грабить и бить помогает // Время. - 20.09.2018.

4. Намитокова Р. ЮО. Авторские неологизмы: словообразовательный аспект. - Ростов н/Д : Изд-во Рост. ун-та, 1986. $-160 \mathrm{c}$.

5. «...Пожселания, приправленные криминальной романтикой» // Время. -05.01 .2018 . - С. 3.

6. Плотникова Л. Н. Динамический аспект исследования неузуальных образований // Лексическая и грамматическая семантика : материалы республиканской научной конференции. - Белгород, 1998. - С. 127-130.

7. Пляж на снегу // Время. - 08.11.2018. - С. 16.

8. Старуха ИЗВЕРГиль // Жизнь за всю неделю. Казахстан. - № 48. - 04.12.2018.

9. Суд слезам не верит // Время. - 22.11. 2018.

10. Титова Н. В. Семантика и поэтическая функция окказиональньх слов : автореф. дис... канд. филол. наук : 10.02.01. - Челябинск, 2006. -22 с.

11. Трейд-ин. Эффективные продажи в автобизнесе [Электронный ресурс]. - Режим доступа : http://www.drivenetwork.ru/articles?id=13.

12. Улуханова И. С. Узуальные и окказиональные единицы словообразовательной системы // Вопросы языкознания. - 1984. - № 1. - С. 44-50.

13. Ханпира Э. Об окказиональном слове и окказиональном словообразовании русского языка // Развитие словообразования русского языка. - М. : Наука, 1966. - С. 153-166.

14. Холод - не тетка // Время. -05.01.2019. - С. 5.

15. Честное бандитское поздравление // Время. - 05.01.2018. - С. 3.

16. ІІеляховская Л. А., Богданов Н. А. Словообразовательный аспект изучения некоторых групा окказионализмов // Новое слово и словарь новьх слов. - Л. : Наука ЛО, 1983 - С. 82-92.

17. Бейсенбай А. Б. Әбіш Кекілбаев пығармаларындағы окказионалдық қолданыстар : филол. ғыл. канд. ... дис. [каз.]. - Астана, 2008. - 24 б.

18. Еспекова Л. Ә. Қадір Мырзалиев поэзиясындағы окказионализмдер : филол. ғыл. канд. ... дис. [каз.]. - Алматы, 1998. - 30 б.

Статья поступила в редакцию 22.05.2019

\section{REFERENCES}

1. Babenko N. G. Okkazional'noe v hudozhestvennom tekste. Strukturno-semanticheskij analiz. - Kaliningrad : Kaliningrad. gos. un-t, 1997. $-84 \mathrm{~s}$.

2. Goryuchie slezy // ZHizn'. - 20.11.2018

3. Im sluzhba grabit' i bit' pomogaet // Vremya. - 20.09.2018. 
4. Namitokova R. Yu. Avtorskie neologizmy: slovoobrazovatel'nyj aspekt. - Rostov n/D : Izd-vo Rost. un-ta, 1986. $-160 \mathrm{~s}$.

5. «...Pozhelaniya, pripravlennye kriminal'noj romantikoj»// Vremya. -05.01.2018. - S. 3.

6. Plotnikova L. I. Dinamicheskij aspekt issledovaniya neuzual'nyh obrazovanij // Leksicheskaya i grammaticheskaya semantika : materialy respublikanskoj nauchnoj konferencii. - Belgorod, 1998. - S. 127-130.

7. Plyazh na snegu // Vremya. -08.11.2018. - S. 16.

8. Staruha IZVERGil' // Zhizn' za vsyu nedelyu. Kazahstan. - № 48. - 04.12.2018.

9. Sud slezam ne verit // Vremya. - 22.11. 2018.

10. Titova $N$. $V$. Semantika i poeticheskaya funkciya okkazional'nyh slov : avtoref. dis... kand. filol. nauk 10.02.01. - Chelyabinsk, 2006. $-22 \mathrm{~s}$.

11. Trejd-in. Effektivnye prodazhi v avtobiznese [Elektronnyj resurs]. - Rezhim dostupa http://www.drivenetwork.ru/articles? id=13.

12. Uluhanova I. S. Uzual'nye i okkazional'nye edinicy slovoobrazovatel'noj sistemy // Voprosy yazykoznaniya. - 1984. - № 1. - S. 44-50.

13. Hanpira E. Ob okkazional'nom slove i okkazional'nom slovoobrazovanii russkogo yazyka // Razvitie slovoobrazovaniya russkogo yazyka. - M. : Nauka, 1966. - S. 153-166.

14. Holod - ne tetka // Vremya. - 05.01.2019. - S. 5.

15. Chestnoe banditskoe pozdravlenie // Vremya. -05.01.2018. - S. 3.

16. Shelyahovskaya L. A., Bogdanov N. A. Slovoobrazovatel'nyj aspekt izucheniya nekotoryh grupp okkazionalizmov // Novoe slovo i slovar' novyh slov. - L. : Nauka LO, 1983. - S. 82-92.

17. Bejsenbaj A. B. Obish Kekilbaev shyғarmalaryndaғy okkazionaldyқ қoldanystar : filol. ғyl. kand. ... dis. [kaz.]. - Astana, 2008. - 24 b.

18. Espekova L. Ә. Қadir Myrzaliev poeziyasyndaғy okkazionalizmder : filol. ғyl. kand. ... dis. [kaz.]. Almaty, 1998. - 30 b.

The article was contributed on May 22, 2019

\section{Сведения об авторах}

Булатбаева Кулжанат Нурымжановна - доктор педагогических наук, профессор кафедры иностранной филологии Евразийского национального университета им. Л. Н. Гумилева, г. Нур-Султан, Казахстан; e-mail: bulatbaeva.kulzhanat $@$ mail.ru

Сарсикеева Гульнар Кусайеновна - кандидат филологических наук, доцент, профессор кафедры иностранной филологии Евразийского национального университета им. Л. Н. Гумилева, г. Нур-Султан, Казахстан; е-mail: gsarsikeieva@gmail.com

Айтжанов Куаныши Бахытжануль - магистрант 2 курса направления подготовки магистрантов «Иностранная филология» (магистерская программа «Рекламный текст как фон окказионального словообразования〉) Евразийского национального университета им. Л. Н. Гумилева, г. Нур-Султан, Казахстан; е-mail: Kuna.ast@mail.ru

\section{Author information}

Bulatbaeva, Kulzhanat Nurymzhanovna - Doctor of Pedagogics, Professor of the Department of Foreign Philology, L. N. Gumilyov Eurasian National University, Nur-Sultan, Kazakhstan; e-mail: bulatbaeva.kulzhanat@mail.ru

Sarsikeeva, Gulnar Kusayenovna - Candidate of Philology, Associate Professor, Professor of the Department of Foreign Philology, L. N. Gumilyov Eurasian National University, NurSultan, Kazakhstan; e-mail: gsarsikeieva@gmail.com

Aytzhanov, Kuanysh Bakhytzhanuly - Second-year Master's Degree Student, Master's Degree Training Program «Foreign Philology» (Master's Degree Program «Advertising Text as Background of Occasional Word Formation»), L. N. Gumilyov Eurasian National University, Nur-Sultan, Kazakhstan; e-mail: Kuna.ast@mail.ru 